\title{
Lightweight timber-framed wall and impact of ventilated cladding on the possibility of reducing summer overheating in Central Europe
}

\author{
Peter Juras ${ }^{1 *}$ \\ ${ }^{1}$ Department of Building Engineering and Urban Planning, Faculty of Civil Engineering, University of Zilina, Univerzitna 8215/1, \\ 01026 Zilina, Slovakia
}

\begin{abstract}
The climate change creates specific problems in the countries, where it was not so hot during the summer periods in the past. In the area of building envelopes, use of more environmental friendly materials comes to the foreground. Having still more strictly requirements in the thermal protection of buildings, use of lightweight wooden walls is increasing. The ratio between load carrying and insulating parts changed. This is also the advantage of timber framed walls. These walls have also some negatives, or create some problems, such as low thermal capacity. In the Central Europe, the indoor summer overheating started to be a serious problem. In this paper, impact of ventilated cladding on the timber frame wooden wall will be analyzed. One composition, with east and south orientation were evaluated. This wall is a part of the experimental measurement, compared with another ETICS type of outdoor finishing layer. Impact of the ventilated air cavity behind the cladding on the thermal regime of the wall is stated.
\end{abstract}

\section{Introduction}

Effort to minimize the heating loses and increase energy efficiency in the new buildings brings several problems. One of these problems is caused by the use of lightweight structures. These are used to maximize the thermal insulation thickness and reduce total thickness in comparison to the traditional combination masonry + ETICS. Usually they are based on the wooden column structure (timber-framed) or created with use of CLT panels. They are often combined with environmental friendly thermal-insulating materials, such as sheep wool, cellulose or hemp. These materials have a small specific heat capacity, which makes them vulnerable against the summer overheating.

Several authors made case studies about the possible overheating in passive buildings [1-5].

By existing climate change $[6,7]$, also in the Central European region, where also Slovakia [8] belongs, this creates a new approach, in which the energy efficiency in winter could not be on the first place. To avoid the overheating, air conditioning should be used more often. This is more energy consuming than the heating [9].

In the past, by the summer overheating in Slovakia there was a problem with the living space under the pitched roof, which was made from wooden rafter and mineral wool insulation. Rest of the building envelope was made from masonry, either from an aerated clay concrete or a clay brick. With use of the lightweight timber-framed wooden wall, possibility of reducing the overheating can be achieved by use of ventilated cladding. In this paper, use of such cladding on the experimental laboratory fragments will be analyzed, which is exposed to the outer climate and the indoor environment is maintained as constant.

\section{Test setup}

The laboratory used for this part of measurements consists of two laboratory rooms with maintained temperature and relative humidity at all time. Each room contains special wall fragments, which consist of five different sections. These sections are timber-framed based with different material compositions. One of the wall is facing towards east, another one to the south. View at the southern wall is shown in Fig. 1.

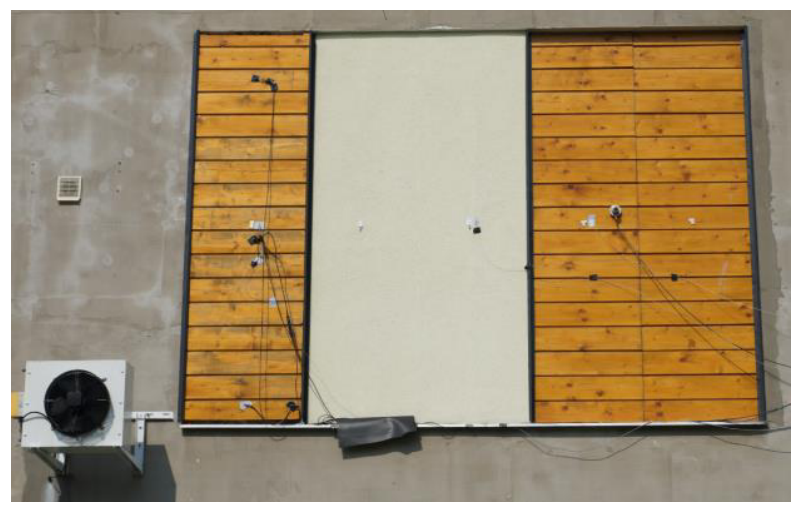

Fig. 1. View at the south-oriented experimental wall. Section with ventilated air gap (blue) and coating (green) are marked.

\footnotetext{
* Corresponding author: peter.juras@,uniza.sk
} 
Within the sections, temperature and relative humidity are monitored. Outer climate is recorded with the own weather station located on the roof of the building [10].

In this case, usual sensor setup [11] was updated with additional sensors in the ventilated cavity and vertically mounted pyranometer. The temperature $(\mathrm{T})$ and relative humidity (RH) in three positions and also the flow velocity were measured in the cavity. Sketch of the wall section with marked sensor positions is presented in Fig. 2 and 3. In Fig. 2 is shown also the legend of measured values in measuring points. For the T/RH measurements, combined sensors Ahlborn FHAD 46 were used. The surface temperature was additionally measured by the thermocouple and flow velocity was measured with Testo 435 datalogger combined with the thermal velocity probe (hot-wire based). Recording interval for this measurement was one minute instead of 15 minutes used for the general experimental wall measurement.

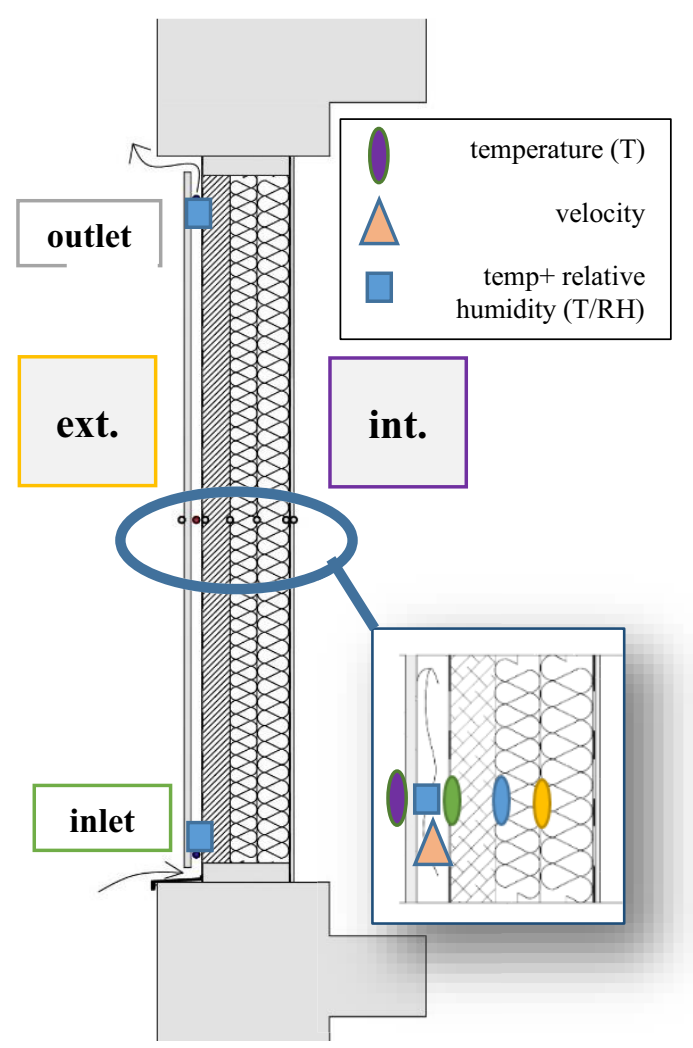

Fig. 2. Sketch of the wall section with ventilated air gap with marked positions of sensors and detail of section center.

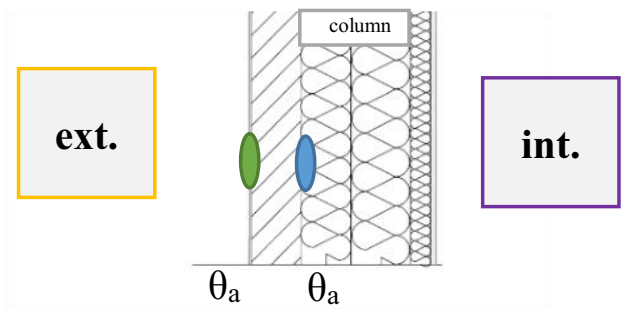

Fig. 3. Sketch of the wall section with exterior coating (Tab. 2). Sensor positions for comparison are marked with same color as in Fig. 2.

\section{Wall composition}

To measure the influence not only on the outdoor surface, which is crucial for the calculation of temperatures within the wall, also the temperature within the wall was compared to the one without cladding (Fig. 1 and 3). Detailed description of the wall sections and research outcomes can be found in $[11,12]$. Composition of section with ventilated cladding (Fig. 2) is described in Tab. 1.

Table 1. Section composition with ventilated air gap (Fig. 2)

\begin{tabular}{|c|c|c|}
\hline Material (from outside) & $\begin{array}{c}\text { Thickness } \\
(\mathrm{mm})\end{array}$ & $\lambda=(\mathrm{W} /(\mathrm{m} . \mathrm{K}))$ \\
\hline Wooden cladding & 28 & 0.18 \\
\hline Ventilated air gap & 40 & - \\
\hline Membrane & 0.05 & 0.35 \\
\hline Mineral fibre insulation & 100 & $0.036-0.039$ \\
\hline Glass fibre insulation & 220 & 0.03 \\
\hline Vapour barrier & 0.05 & 0.35 \\
\hline OSB 3 board P + D & 12 & 0.13 \\
\hline
\end{tabular}

In comparison to this section, such section with coating was chosen, which composition is similar (Fig. 3 ). For the exact comparison, the same short wave radiation absorptivity will be needed. In this case, the coating is bright and the absorptivity obtained with simulation in WUFI software is very low [13].

Composition of this section is shown in Tab. 2.

Table 2. Section composition with coating (Fig. 3)

\begin{tabular}{|c|c|c|}
\hline Material (from outside) & $\begin{array}{c}\text { Thickness } \\
(\mathrm{mm})\end{array}$ & $\lambda=(\mathrm{W} /(\mathrm{m} . \mathrm{K}))$ \\
\hline Silicone coating & 2 & 0.86 \\
\hline Reinforced adhesive layer & 5 & 0.90 \\
\hline Glass fibre board & 100 & $0.036-0.039$ \\
\hline Glass fibre insulation & 220 & 0.03 \\
\hline Hardened phenolic foam & 40 & 0.021 \\
\hline
\end{tabular}

\section{Days selected for comparison}

Due to the limitation (only one velocity probe), it was not possible to compare both wall sections at the same time. Therefore, for comparison on the southward wall served $4^{\text {th }}$ of September (Fig. 4) and for eastern wall $24^{\text {th }}$ of September (Fig. 5).

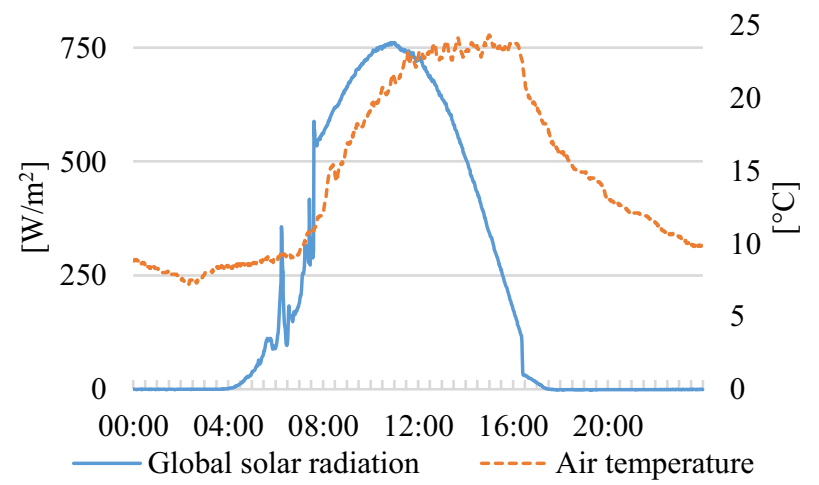

Fig. 4. Recorded weather by weather station for $4^{\text {th }}$ September. 


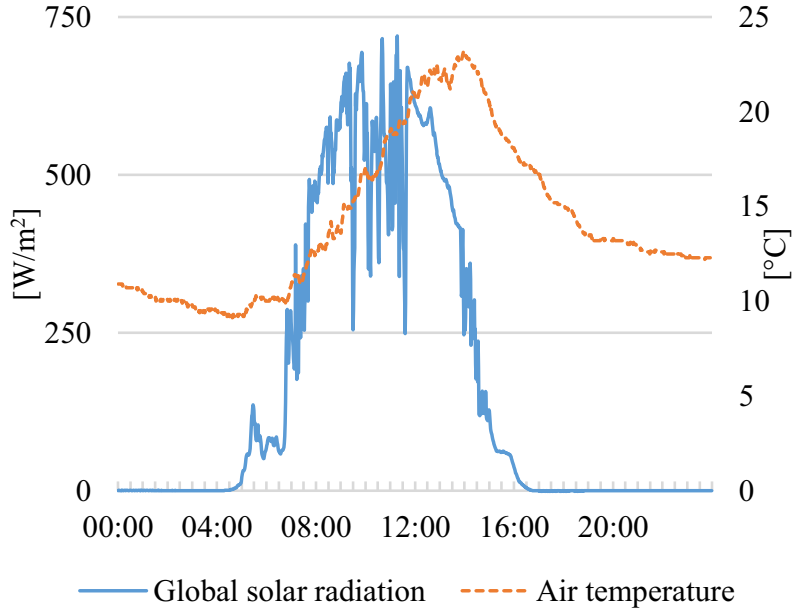

Fig. 5. Recorded weather by weather station for $24^{\text {th }}$ September.

\section{Results and discussion}

Results for selected days are shown in three separated graphs, the first one is showing the different temperatures in the ventilated cavity behind the cladding and increase of velocity of flowing air in this cavity. This is shown in Fig. 6 for south orientation. The second one shows courses of relative air humidity within this cavity (Fig. 7). And finally, comparison between the wall with coating, which has brighter surface than the one with ventilated cladding. The comparison itself (Fig. 8) is made for two positions, first is outdoor surface (for the cladded structure this represents the surface of the membrane), which is marked green in Fig. 2 and 3. Second position is marked blue (Fig. 2 and 3 ) and it is situated on the indoor side of the insulation board (the one, which is in front of the wooden columns).

The results for east-oriented wall are also shown in a similar way than the previous one and they are shown in Fig. 9-11.

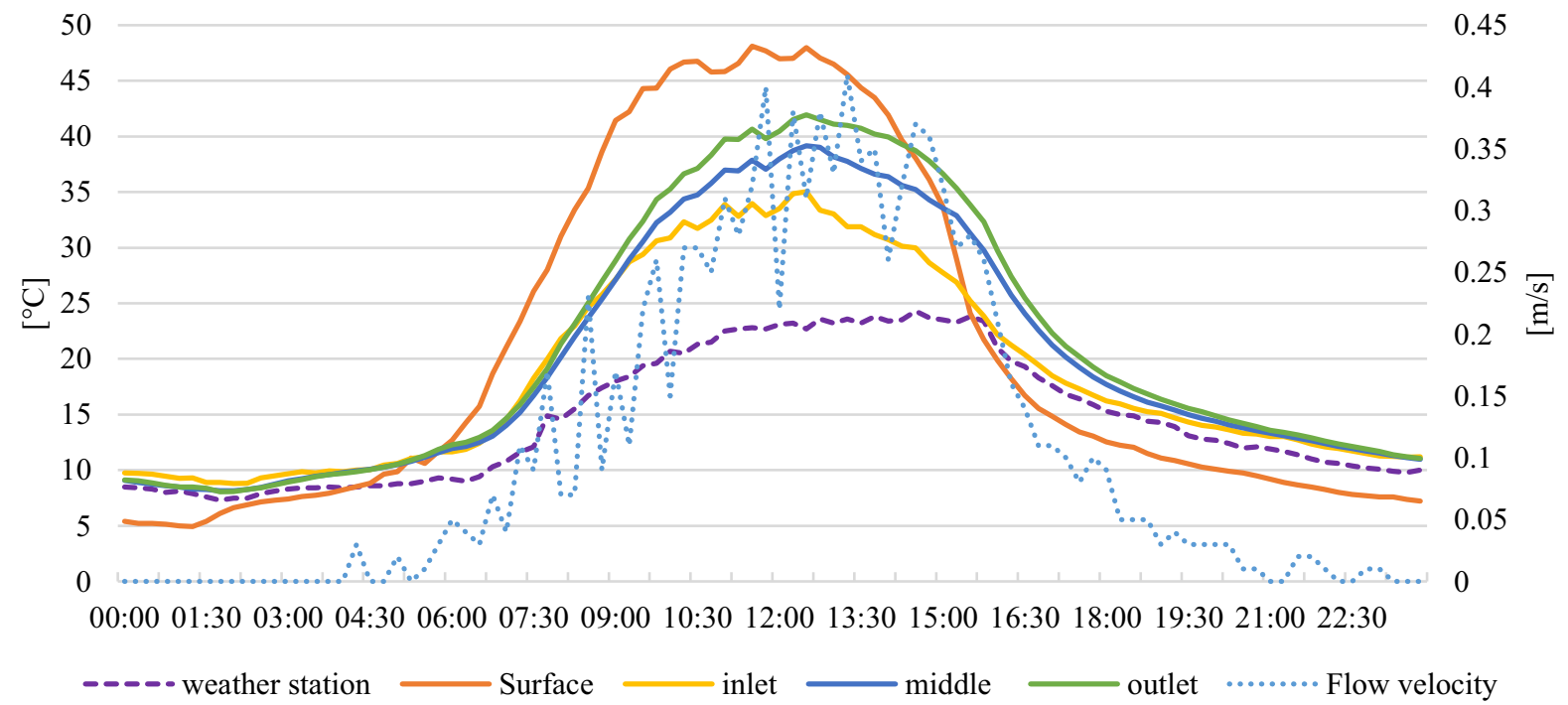

Fig. 6. Courses of temperatures and flow within the cavity on the southward experimental wall on the $4^{\text {th }}$ September.

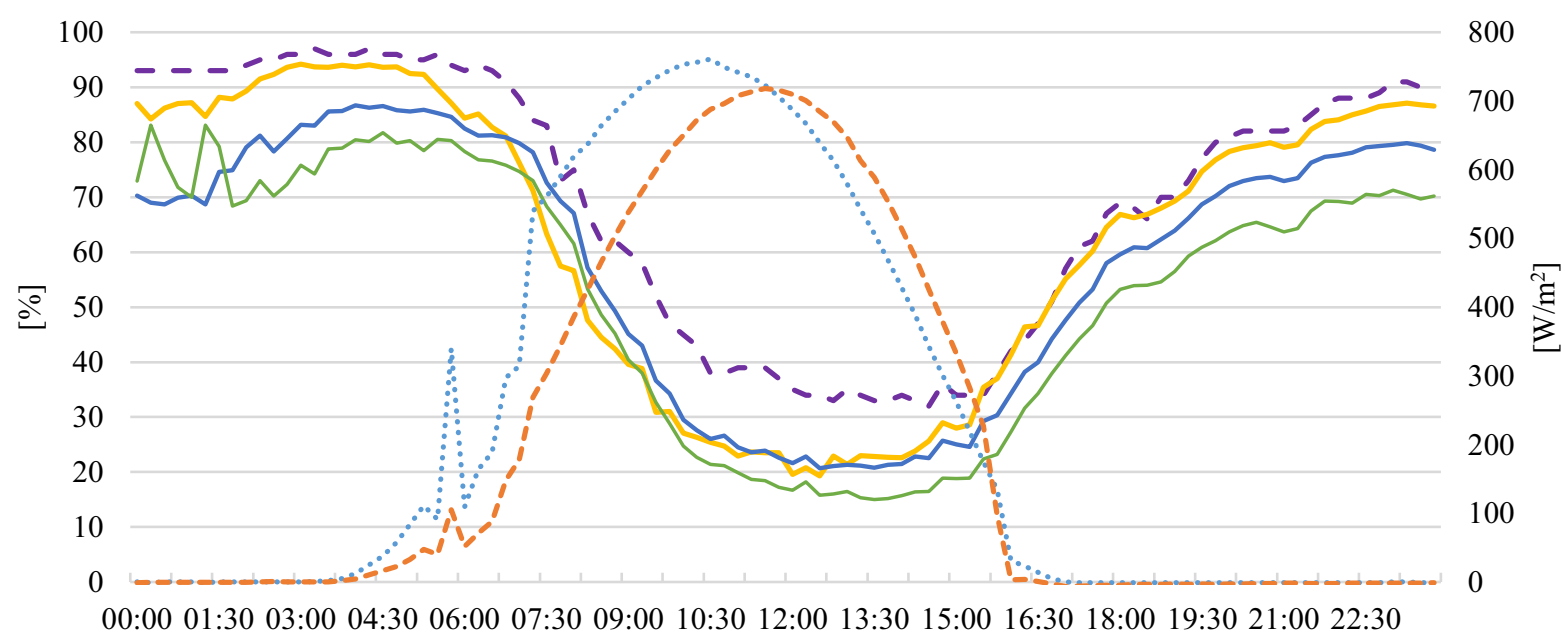

- - - weather station $\longrightarrow$ inlet $\longrightarrow$ middle $\longrightarrow$ outlet $\ldots . .$. Horizontal SR $---\infty$ - vertical SR

Fig. 7. Courses of relative humidity's and global solar radiation on the southward experimental wall on the $4^{\text {th }}$ September. 


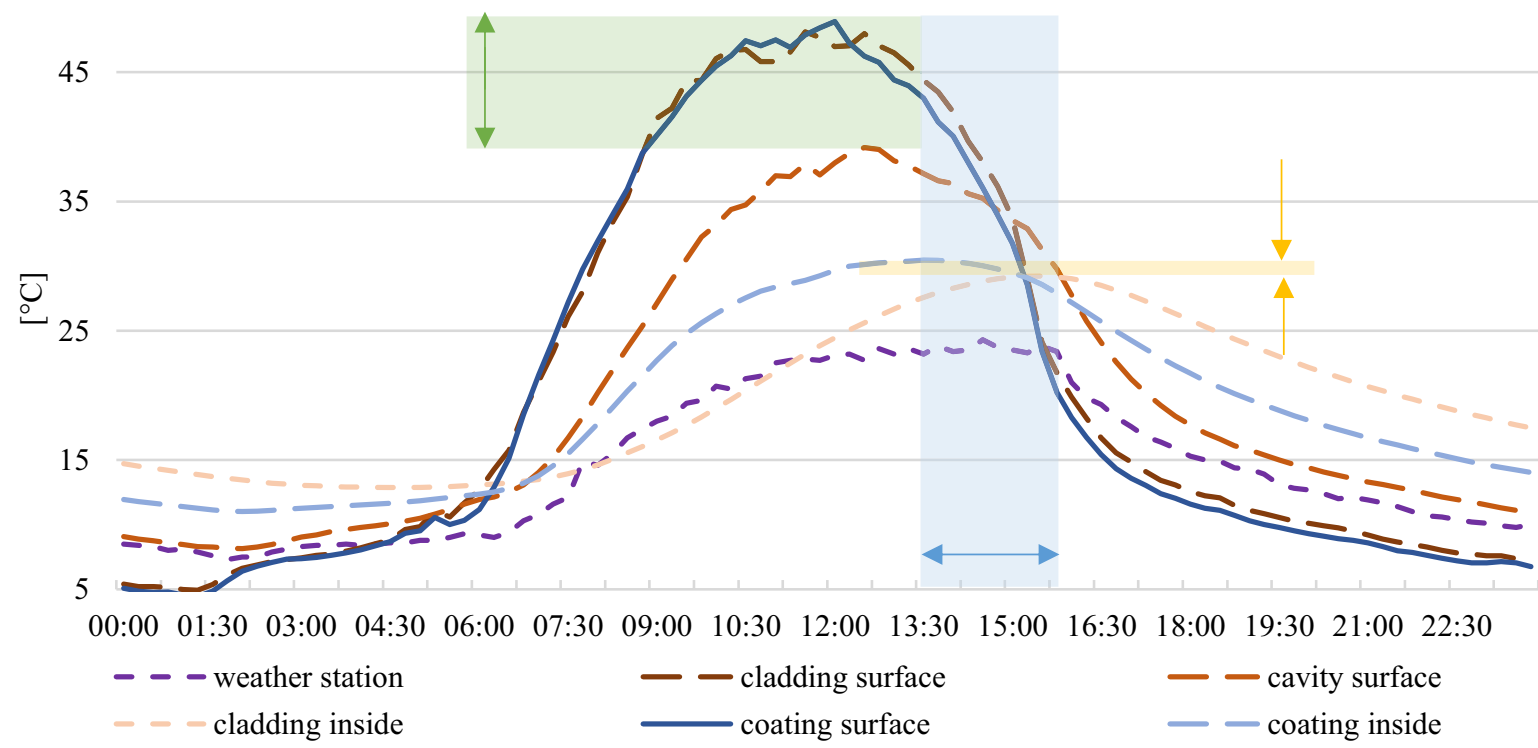

Fig. 8. Comparison of temperature courses for south oriented section with cladding and coating. Difference on the outer surface is 7.9 ${ }^{\circ} \mathrm{C}$, on the interior side of thermal insulation is $1.2^{\circ} \mathrm{C}$ with shift 2.5 hours.

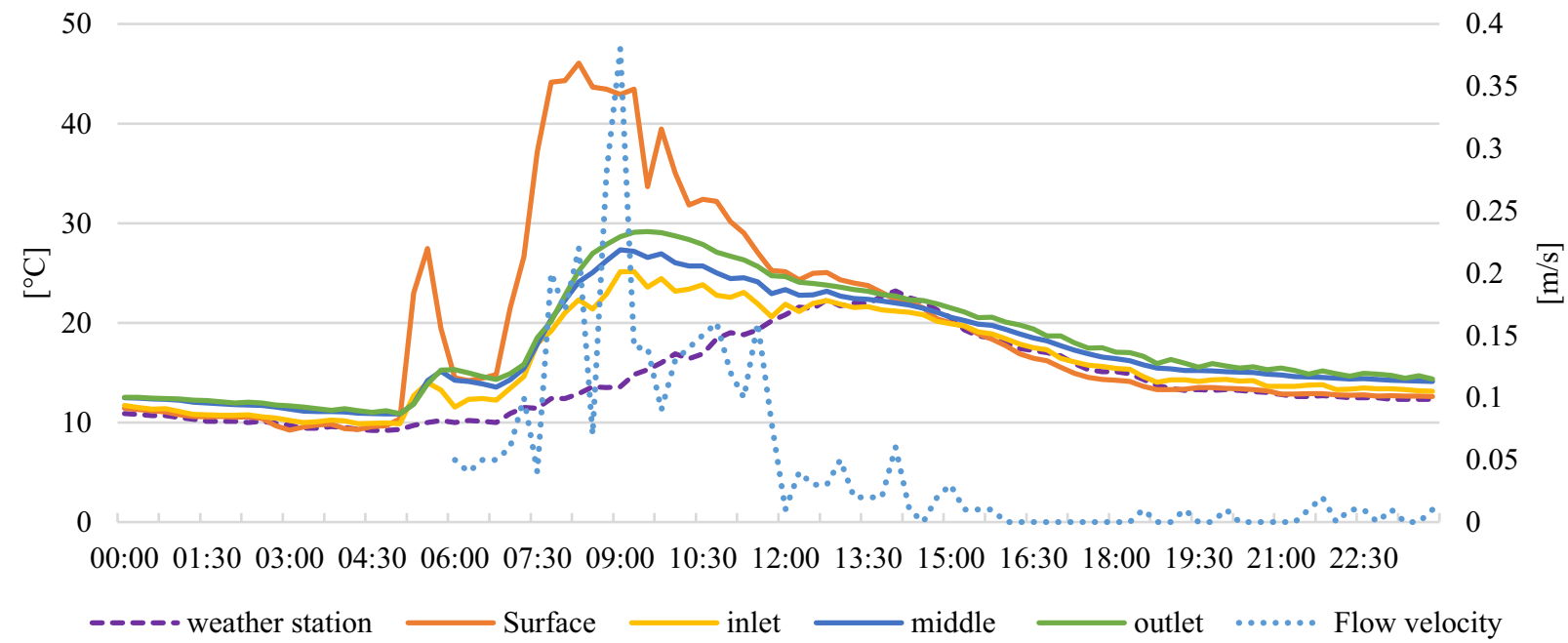

Fig. 9. Courses of temperatures and flow within the cavity on the eastward experimental wall on the $24^{\text {th }}$ September.

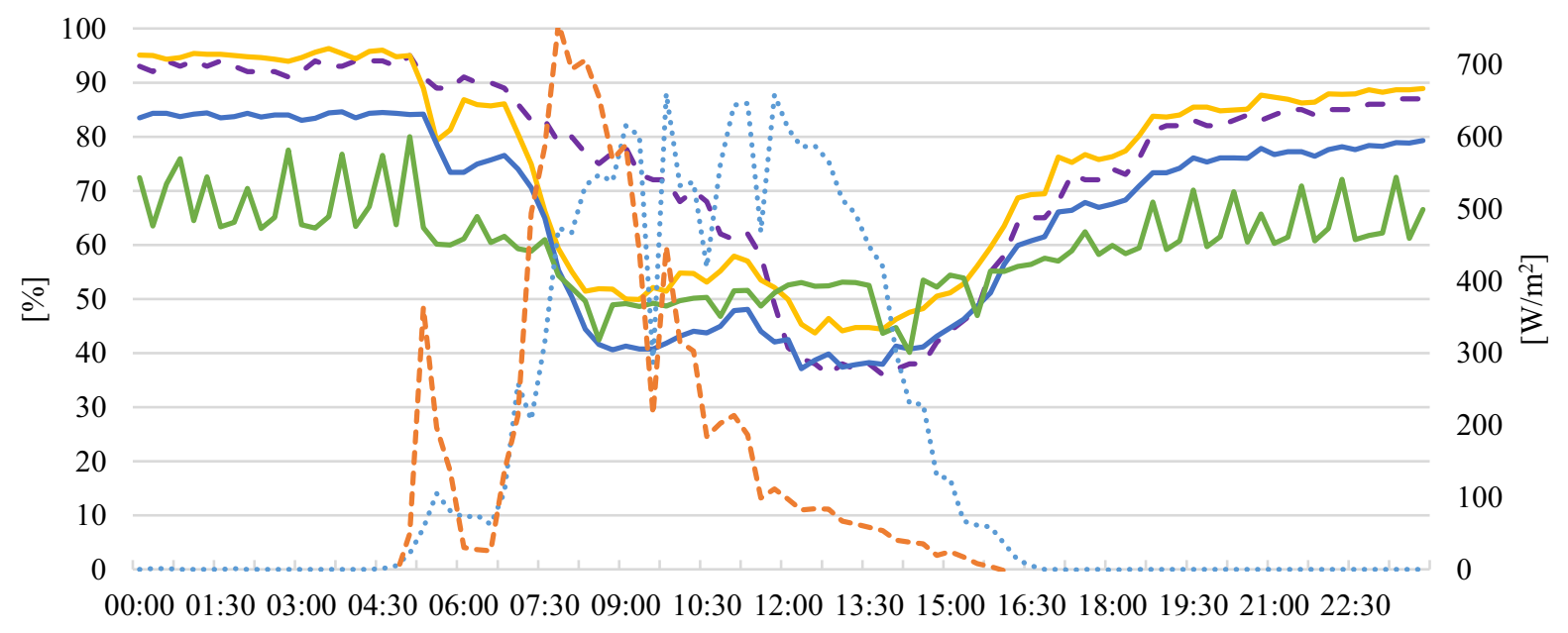

- - - weather station $\longrightarrow$ inlet $\longrightarrow$ middle $\longrightarrow$ outlet $\ldots . .$. Horizontal SR $-\cdots \cdots$ vertical SR

Fig. 10. Courses of relative humidity's and global solar radiation on the eastward experimental wall on the $24^{\text {th }}$ September. 


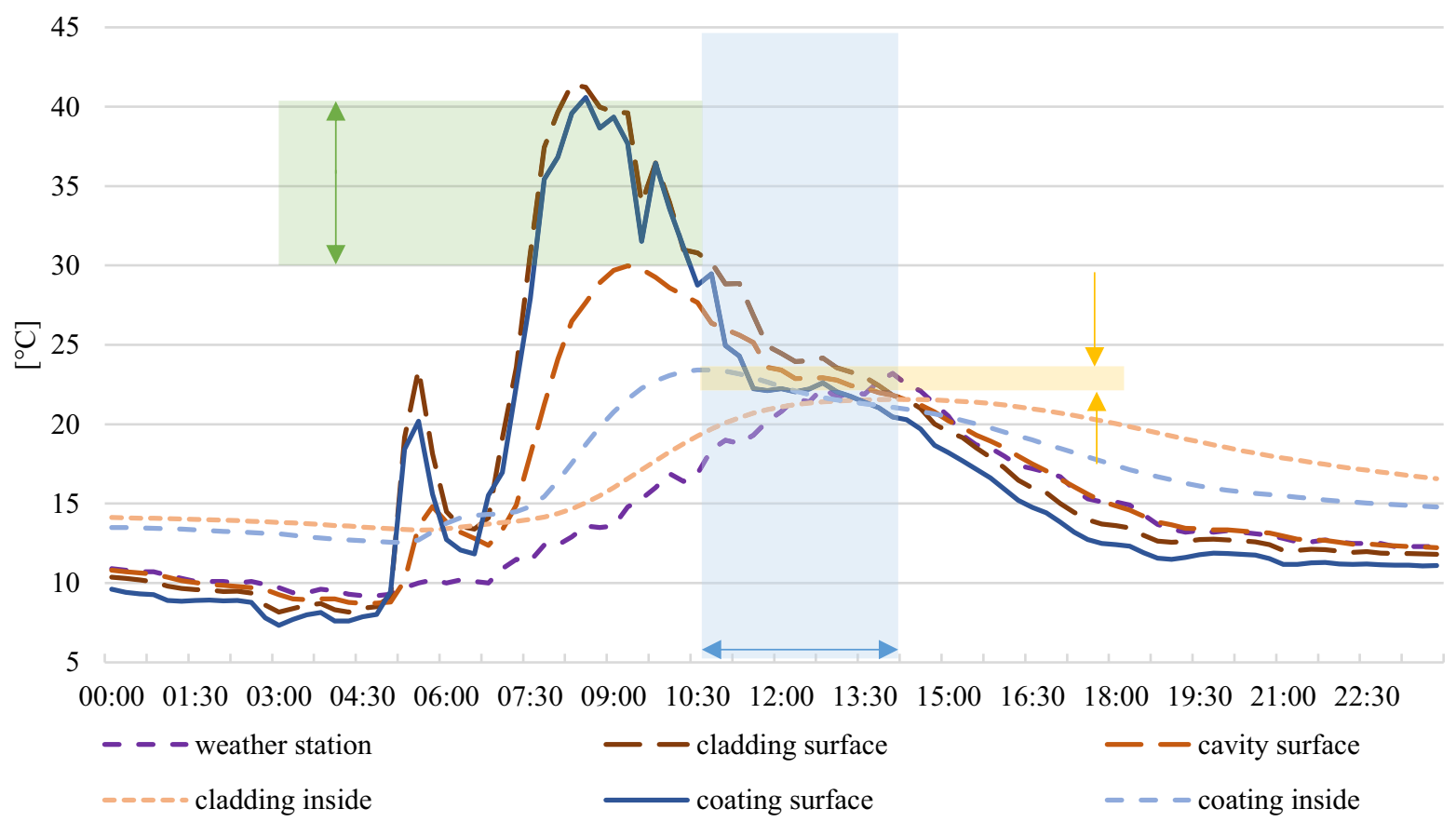

Fig. 11. Comparison of temperature courses for east oriented section with cladding and coating. Difference on the outer surface is 10.1 ${ }^{\circ} \mathrm{C}$, on the interior side of thermal insulation is $1.9^{\circ} \mathrm{C}$ with shift 3.25 hours.

The flow in the cavity is influenced by the direct solar radiation. When the east wall was coming into shade, which is shown on the results from pyranometer mounted on this wall, the velocity started to drop (vertical solar radiation - SR, Fig. 9). Although the global radiation measured on the horizontal plane is still increasing until noon.

Similar results are obtained on the south wall, where the direct solar radiation is influencing the surface for a longer time. Maximum values for velocity are similar, because also the surface temperatures of the cladding are similar. In the morning, the sun is low on horizon and the radiation is more perpendicular to the surface of the wall. Therefore it can be stated that the flow velocity is directly influenced by the direct solar radiation. Influence of the inlet/outlet opening size or the flow amount was not considered at this stage of research.

As the flow velocity increases, also the difference between inlet and outlet air temperatures increases. In the south wall the difference is up to $7{ }^{\circ} \mathrm{C}$, in east wall it is up to $4{ }^{\circ} \mathrm{C}$. This creates also the difference in surface temperatures in the different parts of the wall (with height), but the comparison is made only for the middle of the wall height.

Results of comparison in Fig. 7 and 10 show clearly impact of the cladding. In this case, the temperature drop is not as significant as expected, but it is also caused by not equal colors of the surfaces. If the coating was as dark as the cladding, the outer surface will be heated more and the difference on the interior side will be more affected in favor of the one with cladding.

More interesting in this case is the phase shift of the peaks, which is more than two hours for the south orientation and more than three hours for the east-oriented wall. Also the course has not such curved peaks. The phase shift is a very important parameter in the area of overheating and the results showed that the ventilated cladding can reduce the overheating in some cases.

The results on the indoor surface in the laboratory room cannot be compared because of the air conditioning influence, which keeps the temperature at $20^{\circ} \mathrm{C}$ at all time and that is why the surface temperatures of each section are very similar.

This paper does not analyze the influence of the relative humidity on the cooling effect or the volume of flow in the gap.

\section{Conclusion}

Comparison of the lightweight timber-framed wall with coating and ventilated cladding was made. The results show impact on the temperatures within the wall.

This experiment shows same drawbacks, such as not same color of the outer surface, so direct comparison in this article and found differences will be higher if outer surfaces had same colors. This should be investigated with the simulation in esp-r software in the future. Also the indoor air temperature in the room will be simulated, which was not possible to compare in this laboratory case.

The comparison with use of some kind of MDF boards, which have much higher specific heat capacity will also be interesting. Measured boundary conditions, such as the outdoor climate with direct solar radiation and also surface temperatures and temperatures in the cavity enable the possibility to simulate this type of structure, where the phase shift should be even higher than the measured one in this case with mineral wool insulation.

The research was done with the support of a grant project KEGA 032ŽU-4/2018 and VEGA 1/0673/20. 


\section{References}

1. S. Sharifi, W. Saman, A. Alemu, Identification of overheating in the top floors of energy-efficient multilevel dwellings, J. Energy and Buildings 204, (2019)

2. B. Ozarisoy, H. Elsharkawy, Assessing overheating risk and thermal comfort in state-of-the-art prototype houses that combat exacerbated climate change in UK, J. Energy and Buildings 187, (2019)

3. L.T. Rodrigues, M. Gillott, D. Tetlow, Summer overheating potential in a low-energy steel frame house in future climate scenarios, Sustainable Cities and Society 7, (2013)

4. D. Fosas et al, Mitigation versus adaptation: Does insulating dwellings increase overheating risk?, Building and Environment 143, (2018)

5. R. Ponechal, D. Jurasova, The impact of heat gain schedules on summer overheating in typical insulated dwellings, J. Int. Review of Applied Sciences and Engineering 9, (2019)

6. R. Lorch, Buildings and Climate Change: Accelerating Transformation, IOP Conf. Series: Earth and Environmental Science 290, (2019)

7. D. Jurasova, Analysis of Long-Term Measured Exterior Air Temperature in Zilina, J. CEE 14, (2018)

8. Slovak Hydrometeorological Institute, site: www.shmu.sk

9. O. B. Kazanci, B. W. Olesen, Thermal Indoor Environment and Energy Consumption in a Plusenergy House: Cooling Season Measurements, J. Energy Procedia 78, (2015)

10. D. Staffenova et al., Climate Data Processing for Needs of Energy Analysis. J. Advanced Materials Research: enviBUILD, vol. 1041 pp. 129-134 (2014)

11. D. Staffenova et al., Evaluative Case Study in Lightweight Wooden Wall Research, J. Applied Mechanics and Materials, vol. 887, pp. 56-63 (2019)

12. D. Jurasova, P. Juras, Behaviour of various experimental wall fragments exposed to real climate conditions-temperature measurement, J. Int. Review of Applied Sciences and Engineering 10, (2019)

13. P. Juras, Impact of diffuse solar radiation on HAM simulation accuracy, Matec Web of Conferences 282 (2019) 